\title{
Desain 2-In-1 Catamaran Fishing - Tourism Boat dengan Variasi Deck Convertible di Perairan Jepara
}

\author{
Byan Ajusta Resnaji dan Hasanudin \\ Departemen Teknik Perkapalan, Fakultas Teknologi Kelautan, Institut Teknologi Sepuluh Nopember (ITS) \\ e-mail: hasanudin@na.its.ac.id
}

\begin{abstract}
Abstrak-Kapal ikan merupakan salah satu sarana yang dipergunakan nelayan untuk mencari dan menangkap ikan. Dalam proses penangkapan ikan banyak hal yang mempengaruhi operasinya seperti, pasang surut air laut, cuaca, bulan, dan hal lainnya. Sehingga tidak setiap saat nelayan dapat melakukan operasi penangkapan ikan. Oleh karenanya pendapatan nelayan dari hasil tangkap ikan tidak senantiasa stabil. Hasil tangkapan ikan nelayan Jepara mengalami penurunan pada kurun waktu terakhir. Di lain sisi, Jepara memiliki potensi wisata pantai yang menarik dan perlu dikembangkan. Untuk menunjang kestabilan pendapatan nelayan Jepara maka diperlukan inovasi desain kapal ikan 2in-1 yang dapat dimanfaatkan untuk menangkap ikan, sekaligus untuk kapal wisata. Konsep desain kapal 2-in-1 ini menggunakan lambung catamaran supaya mendapatkan deck kapal yang lebih luas dan stabil. Konsep desain deck menggunakan prinsip convertible. Desain kapal yang dihasilkan memenuhi analisis teknis yang meliputi stabilitas, trim, dan freeboard. Kapal yang didesain memiliki ukuran Panjang antar Garis Tegak (LPP): 15,4 meter, Lebar (B): 6 meter, Tinggi $(H): 2$ meter, dan Sarat (T): 1 meter dengan kecepatan: 9 knot. Dari ukuran tersebut dan berbagai asumsi yang dilakukan maka didapatkan nilai ekonomis yang sesuai, yaitu harga tiket untuk menaiki kapal 2in-1 sebesar Rp. 100.000.,- dan nilai payback period selama 2 tahun 1 bulan 22 hari. Dengan rute pelayaran dari Pantai Kartini menuju Pulau Panjang dan dilakukan pemberhentian pada titik tertentu dengan total waktu pemberhentian selama 2 jam, kemudian kembali ke Pantai Kartini.
\end{abstract}

Kata Kunci - desain kapal, 2-in-1 catamaran, fishing - tourism boat, convertible deck, pantai Kartini Jepara.

\section{PENDAHULUAN}

$\mathbf{J}^{\mathrm{B}}$ EPARA merupakan sebuah kabupaten yang terletak di ujung utara provinsi Jawa Tengah. Dengan pesona alam khususnya pantai dan lautnya yang menawan, jepara cukup menjadi pusat perhatian bagi para wisatawan dari berbagai penjuru. Tentunya potensi ini dikelola sebagai pendapatan penduduk Jepara.

Selain sisi dari keindahan Jepara, wilayah laut ini juga digunakan sebagai sumber mata pencaharian yang lain, yaitu menangkap ikan. Dilibatkan beberapa faktor untuk pertimbangan dalam melakukan pelayaran menangkap ikan. Iklim, cuaca, pasang surut air laut, bahkan perhitungan bulan pun menjadi faktor - faktor yang perlu diperhatikan. Sehingga ada kalanya nelayan tidak berlayar untuk mencari ikan. Tentunya hal tersebut mempengaruhi pendapatan penduduk [1].

Cuaca ekstrim melanda perairan laut utara Jepara selama beberapa kurun waktu terakhir. Akibatnya hasil tangkapan merosot tajam, berdampak pada harga ikan yang melonjak naik. Jika pada situasi normal, hasil tangkapan yang dilelang dapat mencapai 1 juta rupiah sekali melaut. Namun, pada kondisi tersebut hasil tangkapannya hanya menghasilkan ratusan ribu rupiah.

Potensi yang ada sebenarnya mampu dikembangkan dan dimanfaatkan sebaik mungkin untuk menambah penghasilan agar kestabilan pendapatan lebih terjaga. Oleh karena itu, pada penelitian desain kapal 2-in-1 catamaran fishing - tourism boat dengan deck convertible ini dapat dijadikan sebagai solusi untuk menambah pendapatan nelayan dan menunjang penghasilan yang lebih stabil.

\section{TINJAUAN PUSTAKA}

\section{A. Kapal Ikan}

Menurut Kepmen nomor : KEP. 02/MEN/2002. Kapal Perikanan adalah kapal atau perahu atau alat apung lainnya yang digunakan untuk melakukan penangkapan ikan termasuk melakukan survai atau eksplorasi kelautan. Klasifikasi kapal perikanan baik ukuran, bentuk, kecepatan maupun konstrusinya sangat ditentukan oleh peruntukkan kapal perikanan tersebut. Demikian pula dengan kapal penangkap, masing- masing memiliki ciri khas, ukuran, bentuk, kecepatan dan perlengkapan yang berbeda. Kapal perikanan secara umum terdiri dari: Kapal Penangkap Ikan, Kapal Pengangkut Hasil Tangkapan, Kapal Survey, Kapal Latih, dan Kapal Pengawas Perikanan [2].

Kapal perikanan merupakan salah satu jenis kapal yang mempunyai fungsi berbeda dengan kapal-kapal lainnya seperti kapal barang (general cargo), kapal tanker, kapal container maupun kapal penumpang (passengers ship). Kapal perikanan mempunyai fungsi untuk menangkap, mengejar, menyimpan, dan mengangkut ikan hasil tangkapan. Dengan demikian faktor kecepatan (speed), olah gerak (maneuverability), kelaiklautan (sea worthiness), lingkup area penangkapan (navigable area), konstruksi, mesin penggerak (propulsion engine), perlengkapan tangkap (fishing equipment), perlengkapan pemrosesan dan lainnya adalah merupakan faktor keistimewaan kapal perikanan [3].

\section{B. Catamaran}

Catamaran merupakan salah satu dari jenis kapal specialpurpose. Kapal special-purpose sendiri adalah kapal yang tidak termasuk kategori utama dari jenis kapal pada umumnya karena kondisi spesifik dari desain dan operasionalnya. Sebagai contoh tugboats, icebreakers, fishing vessels, dan offshore support vessels. Demikian juga dengan kapal tidak konvensional dengan desain yang bergantung dengan jenis, ukuran, dan kecepatan. Seperti multi-hull vessel: catamarans, trimarans, pentamarans, dll [4]. 
Kapal catamaran merupakan termasuk jenis tipe kapal multi-hull yang memiliki dua lambung (demihulls) yang dihubungkan oleh suatu konstruksi sehingga menjadi satu kesatuan sebagai satu kapal. Kedua demihulls ini tersusun dengan rangkaian bridging. Struktur bridging ini merupakan sebuah keuntungan catamaran karena menambah tinggi lambung timbul (freeboard). Sehingga kemungkinan terjadi deck wetness dapat dikurangi [5].

Catamaran memiliki beberapa kelebihan jika dibandingkan dengankapal monohull meliputi memiliki tahanan gesek yang lebih kecil; luas geladak yang lebih luas; stabilitas kapal yang lebih tinggi; sudut oleng yang relatif rendah. Selain itu juga katamaran juga memiliki kekurangan seperti: masih tergolong teknologi yang baru; teknik pembuatan yang lebih rumit; kemampuan maneuver yang kurang baik jika dibandingkan dengan kapal monohull.

\section{Catamaran Fishing Vessel}

Salah satu bentuk upaya efisiensi pengunaan kapal ikan adalah memperbaiki performanya. Perubahan performa dapat dibuktikan dengan mengubah bentuk lambung dari monohull menjadi bentuk katamaran. Kelebihan kapal katamaran yaitu memiliki stabilitas lebih baik, daya jelajah yang lebih jauh, dan tahanan serta gesekan kapal lebih kecil dibandingkan kapal berbentuk monohull [6].

Pada perhitungan stabilitas, hasil menunjukkan kapal ikan katamaran mempunyai stabilitas yang stabil titik $M$ berada diatas titik G pada semua kondisi. Pada perhitungan olah gerak, kapal ikan katamaran memiliki olah gerak yang baik terbukti tidak terjadi deck wettnes. Karena memiliki dua buah lambung, kapal ini memiliki stabilitas melintang yang lebih baik dibandingkan dengan kapal monohull, sehingga pada saat proses hauling kapal akan lebih aman karena kemiringan kapal lebih kecil dibandingkan kapal monohull. Hasil dari penelitian yang dilakukan mengindikasikan bahwa memungkinkan katamaran memiliki hambatan (resistance) lebih kecil daripada monohull pada displacement yang sama. Sebuah rancangan kapal ikan katamaran, seperti yang dimaksudkan, mengindikasikan pengaturan equipment untuk penangkapan ikan pada deck secara bebas [7].

\section{Sistem Convertible Deck}

Sistem convertible deck adalah sistem yang memanfaatkan luasnya deck pada kapal ikan dengan tipe lambung katamaran. Pada deck tersebut dapat difungsikan menjadi dua yaitu, sebagai tempat equipment untuk penangkapan ikan saat kapal difungsikan sebagai kapal ikan dan sebagai tempat duduk untuk pengunjung atau wistawan ketika kapal difungsikan sebagai kapal wisata.

\section{TINJAUAN WILAYAH}

Jepara merupakan salah satu kabupaten di Jawa Tengah. Dimana letak sebelah barat dan utara berbatasan dengan Laut Jawa, sebelah timur berbatasan dengan Kabupaten Kudus dan Pati dan sebelah Selatan berbatasan dengan Kabupaten Demak.

Salah satu destinasi wisata yang cukup terkenal di Jepara ialah Pantai Kartini. Lokasi dari pantai kartini dapat dikatakan strategis dimana dekat dengan pelabuhan utama Jepara dan tidak begitu jauh dari pusat kota. Hingga tahun 2016 lalu angka pengujung yang berwisata di pantai ini menunjukan kenaikan. Namun sangat disayangkan, 2017 tahun lalu menjadi titik merosotnya jumlah pengunjung di Pantai Kartini.

Sebagai rute pelayaran kondisi kapal wisata didapatkan jalur dari Pelabuhan Kartini Jepara menuju ke Pulau Panjang lalu mengelilingi pulau tersebut dan kembali ke Pelabuhan Kartini Jepara dengan melewati tepian Pantai Kartini. Jarak yang didapat dari pelayaran tersebut diperkirakan sejauh 4,42 mil atau setara dengan $7,11 \mathrm{~km}$.

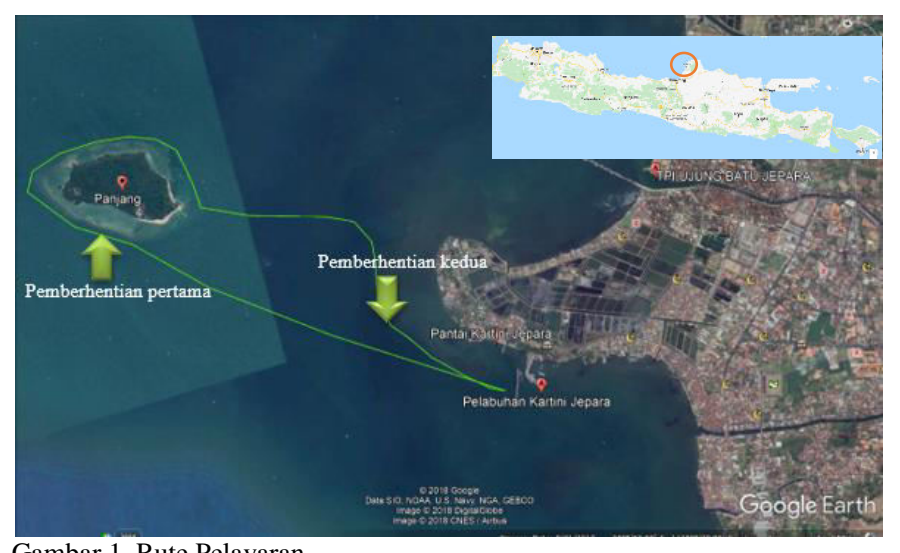

Gambar 1. Rute Pelayaran.

Sedangkan untuk rute pelayaran sebagai kapal ikan ditentukan sesuai dengan peraturan yang telah ditetapkan oleh Menteri Kelautan dan Perikanan RI Nomor: PER.02/MEN/2011. Isi dari peraturan tersebut mengenai jalur penangkapan ikan di wilayah laut Indonesia. Untuk kapal 2-in1 catamaran ini menggunakan jalur II yaitu antara 4 mil laut hingga 12 mil laut dari tepi pantai. Sehingga didapatkan perkiraan jarak yang ditempuh untuk pelayaran hingga kembali ke TPI Ujung Batu Jepara sejauh $32 \mathrm{~km}$.

\section{METODOLOGI PENELITIAN}

\section{A. Pengumpulan Data}

Pengumpulan data ini dilakukan dengan mengumpulkan data secara langsung (primer) dan tidak langsung (sekunder). Data-data ini yang nantinya akan menjadi parameter dari proses desain kapal. Data yang dibutuhkan antara lain:

a. Jenis kapal ikan yang digunakan

b. Data hasil perikanan tangkap Kab. Jepara

c. Data pengunjung wisata Pantai Kartini

d. Kuesioner wisatawan yang ingin melakukan pelayaran dengan kapal 2-in-1 catamaran.

\section{B. Analisis Data}

Tujuan dari analisis data ini adalah untuk memperoleh nilai payload kapal yaitu muatan ikan atau jumlah penumpang yang akan diangkut oleh kapal tersebut.

\section{Ukuran Utama Kapal}

Dalam penentuan ukuran utama kapal, digunakan metode Point Based Design dimana dilakukan penentuan satu ukuran utama kapal kemudian diperiksa apakah semua ketentuan dan persyaratan yang ada dapat terpenuhi. Apabila terdapat ketentuan dan persyaratan yang tidak terpenuhi, maka ukuran 
utama dirubah / dikoreksi hingga semua ketentuan dan persyaratan yang ada terpenuhi.

\section{Analisis Teknis}

Perhitungan teknis yang dilakukan meliputi perhitungan rasio ukuran utama, perhitungan nilai hambatan, perhitungan kebutuhan daya kapal, pemilihan mesin, perhitungan berat, koreksi displacement, koreksi Freeboard, trim, dan stabilitas kapal.

\section{E. Desain Model}

Pada tahap ini dilakukan perencanaan terhadap kapal ini sehingga didapatkan desain yang sesuai dengan karakteristik perairan di daerah pelayaran dan dapat diaplikasikan secara optimal. Perencanaan yang dilakukan adalah sebagai berikut:

a. Desain Rencana Garis

b. Desain Rencana Umum

c. Desain Safety Plan

d. Desain Model 3 Dimensi

\section{F. Analisis Ekonomis}

Analisis ekonomis ini bertujuan untuk mengetahui nilai ekonomis dari proses pembuatan kapal penumpang, sehingga dapat diperkirakan harga jual atau harga tiket yang sesuai.

\section{G. Hasil Penelitian}

Setelah dilakukan analisis dan desain model yang sudah sesuai dapat diperoleh hasil penelitian. Hasil penelitian ini yang dapat dijadikan referensi untuk penelitian selanjutnya.

\section{H. Bagan Alir}

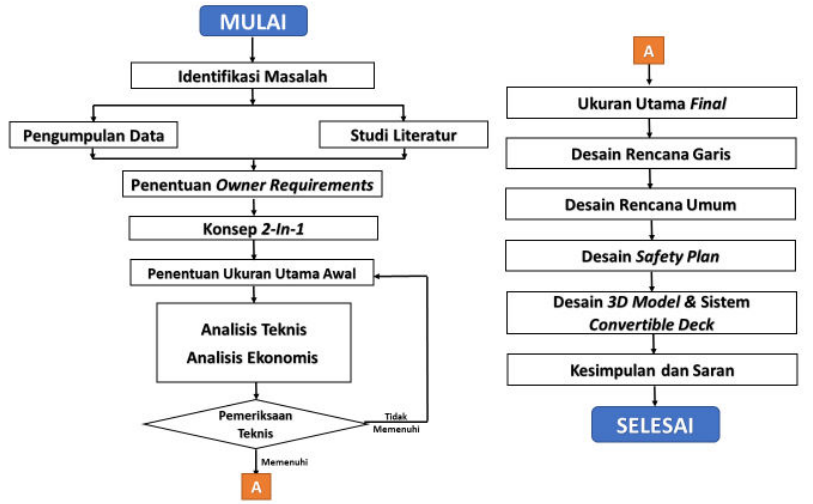

Gambar 2 Bagan Pengerjaan Desain Kapal 2-In-1 Catamaran.

\section{ANALISIS TEKNIS}

\section{A. Penentuan Owner Requirement}

Owner Requirements atau biasa disebut dengan OR merupakan tahapan dasar yang diperlukan untuk mendesain sebuah kapal. OR sendiri berisi mengenai hal-hal dasar penting yang menjadi syarat sebagai ketentuan dalam mendesain. Misalnya rute pelayaran, muatan atau payload, jarak pelayaran, dan lain-lain.

Jenis muatan yang telah ditentukan untuk kapal ini terdapat 2 macam, yaitu orang ketika difungsikan sebagai kapal wisata dan ikan ketika difungsikan sebagai kapal ikan. Dari 2 jenis muatan yang ditentukan ini tentunya memiliki 2 perbedaan pada payload yang didapatkan.
Berdasarkan data-data yang telah didapatkan dan estimasi ketertarikan pengunjung Pantai Kartini untuk menaiki kapal 2in-1 catamaran ini, diperkirakan dalam sekali perjalan dapat menampung maksimal 20 orang. Untuk asumsi berat penumpang sesuai dengan DSC - Code of Safety, Appendix II - Passenger Loading tahun 2014 ditentukan sebesar $75 \mathrm{~kg}$, ditambah dengan asumsi berat bahan makanan dan perlengkapan perorang sebesar $16,6 \mathrm{~kg}$ sesuai dengan perhitungan. Sehingga payload yang didapatkan ketika difungsikan sebagai kapal wisata adalah sebesar $1832 \mathrm{~kg}$ atau 1,832 ton.

Selanjutnya menentukan payload ketika difungsikan sebagai kapal ikan. Dilakukan dengan cara menentukan ruang muat atau cargo fish yang nantinya akan diletakkan pada kapal. Peneliti menentukan cargo fish tersebut berbentuk box dengan ukuran $2 \mathrm{~m}$ x $1,1 \mathrm{~m} \times 1 \mathrm{~m}$ pada setiap lambung. Dengan ukuran tersebut didapatkan estimasi ikan yang mampu dimuat tiap box-nya seberat $700 \mathrm{~kg}$. Maka untuk total muatan ikan yang dapat diperkirakan memiliki muatan $1400 \mathrm{~kg}$ atau 1,40 ton.

\section{B. Penentuan Ukuran Utama Kapal}

Untuk menentukan ukuran utama kapal 2-in-1 catamaran ini dilakukan dengan metode point based design. Metode tersebut dilakukan dengan cara mencari atau merencanakan satu ukuran utama yang sesuai dengan OR. Selanjutnya dari ukuran utama tersebut dilakukan pemeriksaan apakah memenuhi persyaratan dan ketentuan atau tidak. Apabila tidak memenuhi persyaratan dan ketentuan maka pada ukuran utama tersebut dilakukan perubahan atau koreksi hingga memenuhi persyaratan dan ketentuan yang ada. Dalam proses ini tidak dilakukan optimasi. Sehingga ukuran utama yang didapatkan sebagai berikut.

Tabel 3 .

\begin{tabular}{ccc}
\multicolumn{3}{c}{ Ukuran Utama Kapal } \\
\hline \hline $\mathrm{LoA}=$ & 16,00 & $\mathrm{~m}$ \\
\hline $\mathrm{Lpp}=$ & 15,4 & $\mathrm{~m}$ \\
$\mathrm{~B}_{0}=$ & 6,0 & $\mathrm{~m}$ \\
$\mathrm{~T}_{0}=$ & 1,0 & $\mathrm{~m}$ \\
$\mathrm{H}_{0}=$ & 2,0 & $\mathrm{~m}$ \\
$\mathrm{~B} 1_{0}=$ & 1,59 & $\mathrm{~m}$ \\
$\mathrm{~S}=$ & 4,41 & $\mathrm{~m}$ \\
$\mathrm{Vs}=$ & 9,0 & knots \\
\hline \hline
\end{tabular}

\section{Perhitungan Awal}

Perhitungan awal yang dilakukan adalah perhitungan Froude Number, perhitungan coefficient $(\mathrm{Cb}, \mathrm{Cm}, \mathrm{Cp}$, dan Cwp) serta displacement dan volume displacement [8].

\section{Hambatan dan Propulsi Kapal}

Perhitungan hambatan total dilakukan dengan metode Insel dan Molland [9]. Didapatkan nilai hambatan totalnya sebesar 9,8 kN. Setelah nilai hambatan total (Rt) diketahui dapat dihitung nilai power yang dibutuhkan untuk menggerakkan kapal sebesar 98,72 HP [10]. Karena Kapal menggunakan Twin Screw maka nilai powernya dibagi dua menjadi 49,36 HP. Sehingga dilakukan pemilihan mesin dengan power sebesar $50 \mathrm{HP}$.

\section{E. Perhitungan Berat Kapal}

Perhitungan berat kapal dibagi dua yaitu DWT dan LWT dimana DWT adalah berat muatan kapal dan consumable serta 
LWT adalah berat baja kapal kosong ditambah permesinan dan equipment. Dengan nilai total seperti yang dijelaskan di Tabel 3 yaitu 12.92 ton.

Tabel 3.

Koreksi Displacement

\begin{tabular}{cccc}
\hline \hline \multicolumn{4}{c}{ Total Berat Kapal (DWT + LWT) } \\
\hline No & Komponen Berat Kapal & Value & Unit \\
1 & Berat Kapal Bagian DWT & 6,26 & ton \\
2 & Berat Kapal Bagian LWT & 8,09 & ton \\
& Total & 12.92 & ton \\
\hline \hline
\end{tabular}

\section{F. Trim}

Berdasarkan SOLAS Chapter II-1, Part B-1, Reg 5-1, untuk melakukan pemeriksaan trim kapal, nilai trim tidak boleh lebih dari $\pm 0.5 \% *$ LWL [11]. Dari hasil koreksi trim yang diperoleh bersama koreksi stabilitas pada semua kondisi pemuatan, koreksi trim kapal memenuhi seperti terlihat pada Tabel 4 dan Tabel 5.

Tabel 4.

Pemeriksaan Trim Kondisi Kapal Ikan

\begin{tabular}{|c|c|c|c|c|}
\hline \multicolumn{5}{|c|}{ Koreksi Trim Muatan $100 \%$} \\
\hline Trim & $\begin{array}{c}\text { Criteria } \\
\text { Value } \leq 0,5 \% \mathrm{~L}_{\mathrm{wl}}\end{array}$ & $0,5 \% \mathrm{~L}_{\mathrm{wl}}$ & $\begin{array}{c}\text { Value }(m) \\
0,021\end{array}$ & $\begin{array}{c}\text { Status } \\
\text { Pass }\end{array}$ \\
\hline Trim & $\begin{array}{c}\text { Criteria } \\
\text { Value } \leq 0,5 \% \mathrm{~L}_{\mathrm{wl}} \\
\text { Koreksi }\end{array}$ & $\begin{array}{l}0,5 \% \mathrm{~L}_{\mathrm{wl}} \\
0,074 \mathrm{~m}\end{array}$ & $\begin{array}{l}\text { Value }(m) \\
-0,023\end{array}$ & $\begin{array}{c}\text { Status } \\
\text { Pass }\end{array}$ \\
\hline Trim & $\begin{array}{c}\text { Criteria } \\
\text { Value } \leq 0,5 \% \mathrm{~L}_{\mathrm{wl}}\end{array}$ & $\begin{array}{c}0,5 \% \mathrm{~L}_{\mathrm{wl}} \\
0,074 \mathrm{~m}\end{array}$ & $\begin{array}{c}\text { Value }(m) \\
-0,069\end{array}$ & $\begin{array}{c}\text { Status } \\
\text { Pass } \\
\end{array}$ \\
\hline
\end{tabular}

Tabel 5.

Pemeriksaan Trim Kondisi Kapal Wisata

\begin{tabular}{|c|c|c|c|c|}
\hline \multicolumn{5}{|c|}{ Koreksi Trim Muatan $100 \%$} \\
\hline Trim & $\begin{array}{c}\text { Criteria } \\
\text { Value } \leq 0,5 \% \mathrm{~L}_{\mathrm{wl}}\end{array}$ & $\begin{array}{c}0,5 \% \mathrm{~L}_{\mathrm{wl}} \\
0,074 \mathrm{~m}\end{array}$ & $\begin{array}{l}\text { Value }(m) \\
0,071\end{array}$ & $\begin{array}{c}\text { Status } \\
\text { Pass }\end{array}$ \\
\hline Trim & $\begin{array}{c}\text { Koreksi T } \\
\text { Criteria } \\
\text { Value } \leq 0,5 \% \mathrm{~L}_{\mathrm{wl}} \\
\text { Koreksi T }\end{array}$ & $\begin{array}{l}0,5 \% \mathrm{~L}_{\mathrm{wl}} \\
0,074 \mathrm{~m} \\
\text { n Muatan }\end{array}$ & $\begin{array}{c}\text { Value }(m) \\
0,001\end{array}$ & $\begin{array}{c}\text { Status } \\
\text { Pass }\end{array}$ \\
\hline Trim & $\begin{array}{c}\text { Criteria } \\
\text { Value } \leq 0,5 \% \mathrm{~L}_{\mathrm{wl}}\end{array}$ & $\begin{array}{c}0,5 \% \mathrm{~L}_{\mathrm{wl}} \\
0,074 \mathrm{~m}\end{array}$ & $\begin{array}{c}\text { Value }(m) \\
-0,069\end{array}$ & $\begin{array}{c}\text { Status } \\
\text { Pass }\end{array}$ \\
\hline
\end{tabular}

\section{G. Freeboard}

Untuk perhitungan Freeboard, Kapal penumpang katamaran merupakan kapal dengan panjang kurang dari $24 \mathrm{~m}$, kapal termasuk kapal kecil. Sehingga untuk menghitung lambung timbul juga menggunakan ketentuan MGN 280 section 12 Reg12.2.2. Nilai Freeboard diperoleh dengan perhitungan interpolasi dengan data antara panjang kapal 7 meter dan 18 meter. Dari hasil perhitungan interpolasi minimum freeboard, freeboard yang disyaratkan adalah 0,62 $\mathrm{m}$ sedangkan actual freeboard $1,0 \mathrm{~m}$. Sehingga koreksi freeboard ini sesuai dengan yang diisyaratkan [12].

\section{H. Stabilitas}

Analisis stabilitas digunakan untuk mengetahui keseimbangan kapal secara melintang pada beberapa kondisi pemuatan (loadcases). Kriteria stabilitas yang digunakan adalah IMO MSC HSC Code Annex 7 Multihull [13]. Adapun hasil perhitungan stabilitas yang didapat untuk kondisi pemuatan penuh dilihat pada Tabel 6 dan tabel 7. Dapat diketahui bahwa stabilitas kapal memenuhi semua persyaratan untuk loadcase muatan penuh.
Tabel 6. Perhitungan Stabilitas Kapal Ikan

\begin{tabular}{|c|c|c|c|c|}
\hline No & Criteria & Syarat & Value & Status \\
\hline 1 & Area 0 to 30 & $\begin{array}{c}\text { Value } \geq \\
6,9329 \text { m.deg }\end{array}$ & 17,3367 & Pass \\
\hline 2 & $\begin{array}{c}\text { Angle of maximum } \\
\text { GZ(intact) }\end{array}$ & Value $\geq 10^{\circ}$ & 13,6 & Pass \\
\hline 3 & $\begin{array}{c}\text { Area between GZ and } \\
H T L\end{array}$ & $\begin{array}{l}\text { Value } \geq \\
1.6040 \text { m.deg }\end{array}$ & 20,0115 & Pass \\
\hline 4 & $\begin{array}{c}\text { Passenger Crowding } \\
\text { Heeling Arm }\end{array}$ & Value $\leq 10^{\circ}$ & 0,0 & Pass \\
\hline
\end{tabular}

Tabel 7.

Perhitungan Stabilitas Kapal Wisata

\begin{tabular}{|c|c|c|c|c|}
\hline No & Criteria & Syarat & Value & Status \\
\hline 1 & Area 0 to 30 & $\begin{array}{c}\text { Value } \geq \\
6,9329 \text { m.deg }\end{array}$ & 16,5991 & Pass \\
\hline 2 & $\begin{array}{c}\text { Angle of maximum } \\
\text { GZ(intact) }\end{array}$ & Value $\geq 10^{\circ}$ & 13,6 & Pass \\
\hline 3 & $\begin{array}{c}\text { Area between GZ and } \\
\text { HTL }\end{array}$ & $\begin{array}{l}\text { Value } \geq \\
1.6040 \text { m.deg }\end{array}$ & 19,1513 & Pass \\
\hline 4 & $\begin{array}{c}\text { Passenger Crowding } \\
\text { Heeling Arm }\end{array}$ & Value $\leq 10^{\circ}$ & 0,7 & Pass \\
\hline
\end{tabular}

\section{Desain Rencana Garis}

Proses pembuatan desain rencana garis dimulai setelah ukuran utama kapal diketahui. Adapun desain rencana garis kapal penumpang bertenaga surya ini dapat dilihat pada gambar

3.

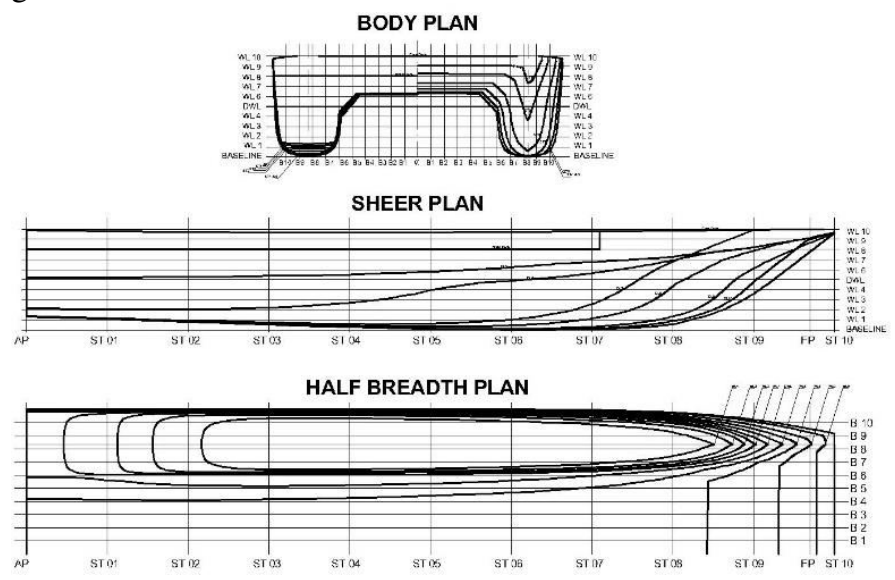

Gambar 3. Desain Rencana Garis.

\section{J. Desain Rencana Umum}

Dari hasil Desain Rencana Garis yang telah dibuat, dapat dilakukan perencanaan peletakan komponen-komponen kapal. Ada beberapa hal yang perlu diperhatikan dalam pembuatan Rencana Umum ini yaitu penataan geladak pada kapal dengan baik agar memberikan kenyaman dan kesesuaian dengan konsep desain yang digunakan [14].

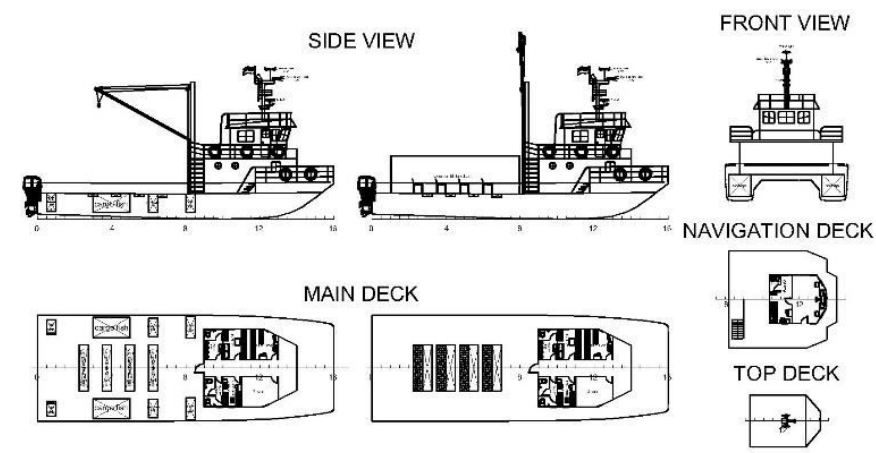

Gambar 4. Desain Rencana Umum. 


\section{K. Safety Plan}

Kapal 2-in-1 catamaran ini di desain untuk mengangkut 20 penumpang dan 3 crew kapal. Sehingga, harus dilakukan perencanaan keselamatan dengan memperhitungkan jumlah manusia yang ada di kapal dan ruang akomodasi yang ada di kapal. Dalam mendesain Safety Plan yang perlu diperhatikan yaitu life saving appliances dan fire control equipment yang mengacu pada SOLAS (Safety of Life at Sea). Desain Safety plan dapat dilihat pada Gambar 5 [15].
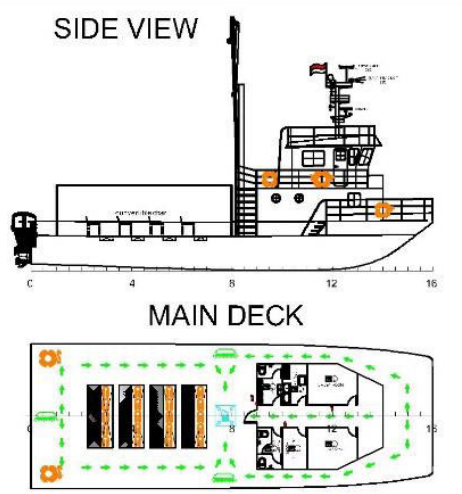

NAVIGATION DECK

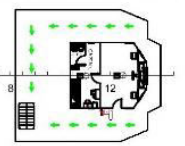

Gambar 5. Desain Safety Plan.

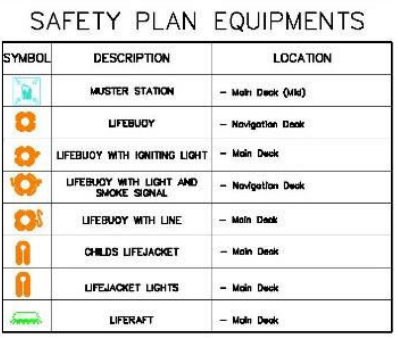

FIRE PLAN EQUIPMENTS

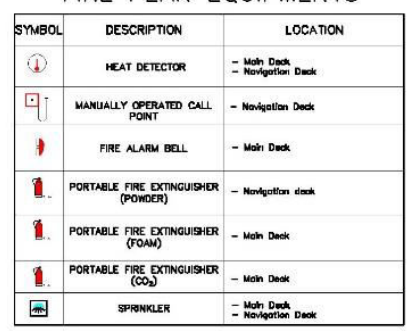

\section{Desain Model 3 Dimensi}

Desain Model 3 Dimensi ini dilakukan untuk melihat hasil perancangan kapal yang telah diperkirakan dan disesuaikan dengan konsep yang ada. Untuk desain 3 dimensi dapat dilihat pada Gambar 6a \& 6b.

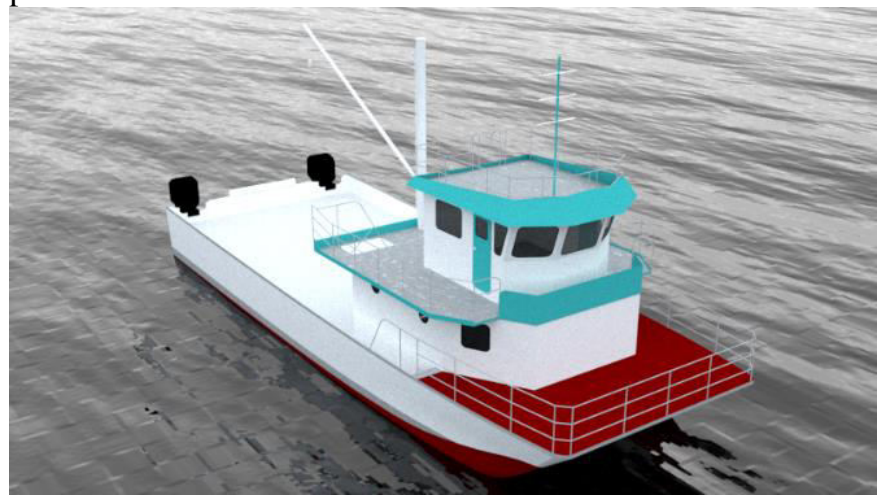

Gambar 6a. Desain 3D Kapal Ikan.

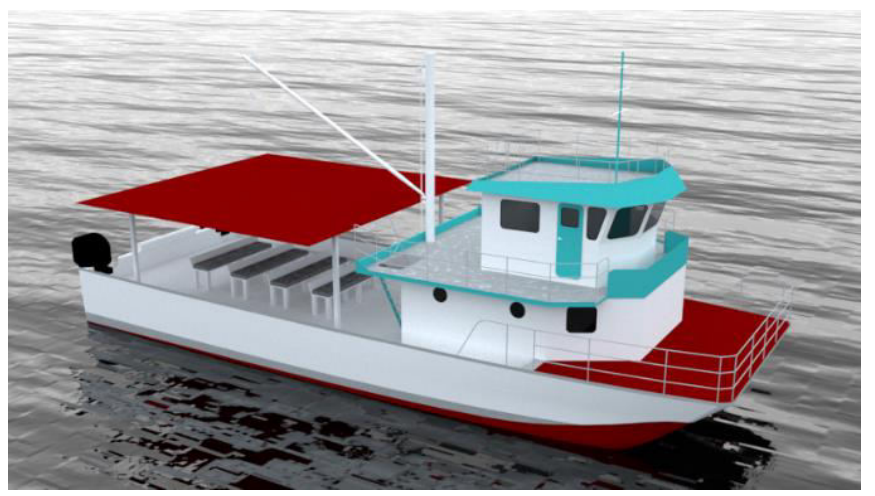

Gambar 6b. Desain 3D Kapal Wisata.

\section{ANALISIS EKONOMIS}

\section{A. Biaya Pembangunan}

Perhitungan (estimasi) biaya pembangunan kapal dilakukan dengan menghitung kebutuhan glass dan resin untuk pembangunan kulit lambung, biaya permesinan, biaya perlengkapan kapal dan biaya keuntungan galangan. Sehingga didapat biaya pembangunan kapal sebesar Rp 1.052.592.818,43,--

\section{B. Biaya Operasional}

Operational cost adalah biaya yang dikeluarkan owner kapal secara rutin. Pada penelitian ini, perhitungan operational cost ditentukan berdasarkan biaya yang harus dikeluarkan owner kapal setiap tahun di antaranya biaya perawatan kapal, asuransi, gaji crew kapal, cicilan pinjaman bank, serta biaya isi ulang baterai dan pembelian air bersih. Sehingga biaya operasional didapat sebesar Rp 634.842.664,- per-tahun.

\section{Analisis Break Event Point}

Analisis break event point digunakan untuk mengetahui apakah pembagunan kapal ini layak untuk dilakukan sesuai dengan periode yang ditentukan. Maka hal yang dibutuhkan ialah perencanaan trip kapal untuk mengetahui frekuensi trip kapal setiap tahun, menentukan harga tiket untuk menghitung pendapatan per tahun, dan penghitungan selisih pemasukan dan pengeluaran kapal setiap tahunnya.

Dari hasil analisis yang telah dilakukan dengan menggunakan berbagai asumsi, didapatkan harga tiket yang dijual sebesar Rp 100.000,-/orang dan Payback Period selama 2 tahun 1 bulan 22 hari.

\section{KESIMPULAN}

Setelah dilakukan analisis teknis dan ekonomis dari penelitian desain kapal 2-in-1 catamaran dengan variasi deck convertible maka dihasilkan:

1) Payload yang sesuai ialah $1400 \mathrm{~kg}$ ikan sebagai kapal ikan dan 20 penumpang sebagai kapal wisata

2) Ukuran utama yang didapat adalah: $\mathrm{Loa}=16,00 \mathrm{~m}, \mathrm{~B}=6,0$ $\mathrm{m}, \mathrm{T}=1,0 \mathrm{~m}, \mathrm{H}=2,0 \mathrm{~m}$

3) Kapal 2-in-1 catamaran memenuhi aturan stabilitas, titik berat, trim, dan freeboard

4) Kapal 2-in-1 catamaran sebagai kapal wisata memiliki harga tiket sebesar Rp. 100.000,-. dengan payback period 2 tahun 1 bulan 22 hari.

\section{DAFTAR PUSTAKA}

[1] Hasanudin and W. A. Niam, "Desain Kapal Ikan di Perairan Laut Selatan Malang," Surabaya, 2017.

[2] M. Huda and B. Santosa, "Analisa Perkiraan Umur Struktur Pada Kapal Ikan Katamaran 10 GT Menggunakan Metode Elemen Hingga," J. Tek. ITS, 2012.

[3] Hasanudin and M. F. I. Afrianta, "Desain Kapal Pengolah Ikan sebagai Bahan Baku Pembuatan Tepung di Perairan Lamongan," Surabaya, 2017.

[4] A. Papanikolaou, Ship Design: Methodologies of Preliminary Design. Springer, 2014.

[5] U. Amriardi, S. Samuel, and M. Iqbal, "Analisa Hambatan Kapal Ikan Tradisional Catamaran Di Perairan Cilacap Karena Perubahan Bentuk Lambung Dengan Pendekatan Lattice Boltzmann Method 
(Lbm)," J. Tek. Perkapalan, 2016.

[6] T. N. C. Bangun and A. Muntaha, "Stabilitas Kapal Ikan Katamaran Sebagai Pengganti Kapal Purse Seine Di Kabupaten Pamekasan Madura Jawa Timur," 2017.

[7] D. Setyawan, I. K. Utama, M. Murdijanto, A. Sugiarso, and A. Jamaluddin, "Development of Catamaran Fishing Vessel," IPTEK J. Technol. Sci., 2010.

[8] MARTEC Application, "Catamaran Design Formulas. 2017. Ukuran Utama Kapal Katamaran,” 2014. [Online]. Available: http://www.catamaransite.com/catamaran_hull_design_formulas.ht mls.

[9] A. F. Molland, M., \& Insel, An Investigation Into the Resistance Components of High Speed Displacement Catamarans. RINA, 1992.
J. D. Manen and P. V. Oossanen, "Principles of Naval Architecture. In E. V. Lewis, Principles of Naval Architecture Second Revision," Jersey City, 1988.

[11] SOLAS, "Chapter II-1, Part B-1, Reg 5-1 - Stability information to be supplied to the master."

[12] MGN280, "Construction standards for small vessels By Alternative Construction Standart."

[13] T. M. and C. Agency, International Code of Safety for High-Speed Craft. London: TSO, 2000.

[14] R. E. Taggart, Ship Design and Construction. The Society of Naval Architects and Marine Engineers, 1980.

[15] M. Ventura, "Safety of Life at Sea (SOLAS)." 1974. 